Acta Cryst. (2002). A58 (Supplement), C333

STRUCTURAL RELATIONS IN THE ADELITE- AND DESCLOIZITESTRUCTURE TYPE

\section{H. Effenberger}

Universitaet Wien Institut Fuer Mineralogie Und Kristallographie

Althanstrasse 14 WIEN OESTERREICH 1090 AUSTRIA

More than a dozen minerals and some synthetic compounds (arsenates, vanadates, silicates, and molybdates) are known to belong to the adelitedescloizite structure type. The double salts are formed by two cations featuring distinct environments. The cation $\mathrm{A}$ is in a [7]- or [8]-coordination $(\mathrm{Na}, \mathrm{Ca}, \mathrm{Pb}$ atoms) whereas the cation B is octahedrally [6] or tetragonal bipyramidally [4 plus 2] coordinated to $\mathrm{O}$ atoms ( $\mathrm{Mg}, \mathrm{Mn}, \mathrm{Fe}, \mathrm{Co}, \mathrm{Ni}, \mathrm{Cu}, \mathrm{Zn}$ atoms). All compounds crystallize orthorhombic. The parental structure is centrosymmetric and exhibits a mono-capped trigonal prism for the coordination polyhedron around the A atoms (descloizite type). An acentric structure variant is known (adelite type); the main difference is the [8] coordination of the A atoms in form of a square antiprism. Further deviations from the centrosymmetric parental structure are moderate. A tendency is observed that the centrosymmetric symmetry goes along with lead-vanadates whereas calcium, arsenate and silicate favour the acentric symmetry. The system $\mathrm{Cd}(\mathrm{II})-\mathrm{Cu}$ (II)arsenate(V) system was investigated under hydrothermal conditions; as a result, a new Cd-member was synthesized. Single-crystal X-ray structure investigations proved that this compound is a centrosymmetric Pnam member of the adelite-descloizite group: $\mathrm{a}=7.415(1), \mathrm{b}=9.016(2), \mathrm{c}=5.890(1) \AA$; NONIUS four-circle diffractometer, CCD detector, capillary-optics collimator, Mo tube, graphite monochromator; R1 $=0.020$, wR2 $=0.046$, total 772 reflections (689 observed reflections); for non-hydrogen atoms anisotropic displacement parameters were refined; the $\mathrm{H}$ atom was found from a difference Fourier map and refined isotropically. The [4 plus 2] coordinated $\mathrm{Cu}$ atoms are located in an inversion centre; they are linked by $\mathrm{O}-\mathrm{O}$ edges to chains parallel to [001]: $\mathrm{Cu}-\mathrm{O}=1.8967(14), 2 \mathrm{x} / 2.0533(16), 2 \mathrm{x} / 2.3083(16) \AA$, 2x. Each of the arsenate tetrahedra link two such chains to a three-dimensional net-work, the average As-O bond distance is $1.6908 \AA$. Cavities house the $\mathrm{A}=\mathrm{Cd}$ atoms: $\mathrm{Cd}-\mathrm{O}$ is 2.224(2) to 2.542(3) $\AA$. The hydrogen bond $\mathrm{O}-\mathrm{H}^{\cdots} \mathrm{O}$ is 2.622(4) $\AA$. Despite similar ionic radii of $\mathrm{Ca}$ and $\mathrm{Cd}$ atoms, the $\mathrm{Ca}$ compound crystallizes acentric.

Keywords: ADELITE GROUP, DESCLOIZITE GROUP, CD(II)-CU(II)ARSENATE(V)

\section{Acta Cryst. (2002). A58 (Supplement), C333 \\ THE DISPLACIVE PHASE TRANSFORMATION IN THE BINARY SYSTEM Sn-Sb}

M. Ellner E. J. Mittemeijer

Max Planck Institute for Metals Research Heisenbergstraße 3 STUTTGART D-70569 GERMANY

The significant berthollidic phase of the binary system $\mathrm{Sn}-\mathrm{Sb}$ is stistaite ( $\mathrm{SnSb}$, $\beta$ phase), stable in the composition range $0.43<\mathrm{xSb}<0.61$ and at temperatures below $698 \mathrm{~K} \mathrm{[1].} \mathrm{The} \mathrm{structure} \mathrm{of} \mathrm{SnSb}$ is of the rhomboedricaly deformed $\mathrm{NaCl}$ type: hR8, $R-3 m, 1 \mathrm{Sn}(\mathrm{a}), 3 \mathrm{Sn}(\mathrm{e}), 1 \mathrm{Sb}(\mathrm{b}), 3 \mathrm{Sb}(\mathrm{d}), \mathrm{a}=0.6123 \mathrm{~nm}$, $\alpha=89.38^{\circ}$ [2]. For compositions $\mathrm{xSb}<0.5$, the atomic positions of antimony are substituted by tin and vice versa for the compositions $\mathrm{xSb}>0.5$. The rhomboedric angle of $\mathrm{SnSb}$ decreases and the unit cell volume increases with increasing valence electron concentration. In the temperature range $523 \mathrm{~K}<\mathrm{T}$ $<597 \mathrm{~K}$, another intermediate phase - $\mathrm{Sn}_{3} \mathrm{Sb}_{2}$ - exists; this high-temperature phase of fixed stoichiometry can be retained neither by quenching of the heattreated alloys nor by means of the liquid-quenching technique. In situ investigation of alloys in the composition range $0.39<\mathrm{xSb}<0.41$ (at temperatures $530 \mathrm{~K}<\mathrm{T}<580 \mathrm{~K}$ ) in a modified Guinier-Simon hightemperature $\mathrm{X}$-ray camera with $\mathrm{CuKa}$ radiation showded that the hightemperature phase $\mathrm{Sn}_{3} \mathrm{Sb}_{2}$ has a non-deformed $\mathrm{NaCl}$ structure: $\mathrm{cF} 8, F m-3 m$, $\mathrm{a}=0.6192(2) \mathrm{nm}$. The symmetry relationship for this displacive phase transformation can be characterized by the equation: $\mathrm{Sn}_{3} \mathrm{Sb}_{2}(\mathrm{cF} 8, F m-3 m)(\mathrm{R})$ $\mathrm{SnSb}(\mathrm{hR} 8, R-3 m)(+\alpha-\mathrm{Sn}(\mathrm{Sb})$, tI4, I41/amd). In the binary and ternary systems containing the $4 \mathrm{~d} / 5 \mathrm{~d}$ elements of the B12 to B16 groups and showing the similar valence electron concentration $(4.50<\mathrm{VEC}<4.75)$, high-pressure phases isotypical with the $\mathrm{NaCl}$ structure also occur: $\mathrm{Cd}_{0.25} \mathrm{Sn}_{0.75} \mathrm{Te}$, $\mathrm{Cd}_{0.5} \mathrm{Sn}_{0.5} \mathrm{Te}, \mathrm{Cd}_{0.25} \mathrm{~Pb}_{0.75} \mathrm{Te}, \mathrm{Cd}_{0.5} \mathrm{~Pb}_{0.5} \mathrm{Te}$ [3].

References

[1]. T. B. Massalski, H. Okamoto, P. R. Subramanian \& L. Kacprzak (1990). Binary alloy phase Diagrams, Second Edition, Vol. 3, ASM International, The Materials Information Society, 3304.

[2]. G. Hägg \& A. G. Hybinette (1935). Phil. Mag., 20, 913.

[3]. R. Marx \& J. Range (1989). J. Less-Common Metals,155, 49.
Acta Cryst. (2002). A58 (Supplement), C333

STRUCTURAL STUDY OF A GRAPHITE-LITHIUM-CALCIUM INTERCALATION COMPOUND

P. Lagrange S. Pruvost C. Herold J.F. Mareche A. Herold

Laboratoire De Chimie Du Solide Mineral (Umr Cnrs 7555) Universite Henri

Poincare Nancy I B.P. 239 Vandoeuvre-Les-Nancy Cedex 54506 France

Lithium is able to intercalate by itself into graphite. This vapour solid reaction leads to a first stage compound, for which the formula is LiC6. All the graphitic intervals are spread apart and are occupied by a monoatomic metal layer. This latter is commensurate with respect to the graphene layers. Calcium leads to a similar intercalation reaction, and the synthesized compound is $\mathrm{CaC}_{6}$. The 2D structure of the intercalated metal layers are exactly the same for both $\mathrm{MC}_{6}$ compounds. But, the graphene interplanar distance is weak for $\mathrm{LiC}_{6}(370$ $\mathrm{pm})$ and larger for $\mathrm{CaC}_{6}(455 \mathrm{pm})$, according to the size of the corresponding cations. Some lithium-calcium liquid alloys are also able to intercalate into graphite. But the first stage ternary compound, that is obtained, is strongly different from $\mathrm{LiC}_{6}$ (or $\mathrm{CaC}_{6}$ ). Indeed, this compound exhibits five-layered intercalated sheets, according to the $\mathrm{Li}-\mathrm{Ca}-\mathrm{Ca}-\mathrm{Ca}-\mathrm{Li}$ c-axis sequence, and its graphene interplanar distance is strongly larger than the former $(776 \mathrm{pm})$. These crystallographic data were obtained of course by X-ray diffraction, but also by neutron diffraction, because lithium is a very light element, so that it is quasi-invisible for the X-rays. The chemical formula of the ternary compound is $\mathrm{LiCa}_{3} \mathrm{C}_{8}$; consequently, its metal content is particularly high, since the carbon/metal ratio comes down to 2 . Intercalated lithium graphite is very interesting, due to its largely expanded use as negative electrode material in the Li-ion batteries.

\section{Keywords: GRAPHITE INTERCALATION LITHIUM}

\section{Acta Cryst. (2002). A58 (Supplement), C333}

\section{$A B$ INITIO INVESTIGATIONS OF $\beta$-Ba(OH $)_{2}$ AND ITS HIGH} PRESSURE PHASE $\beta$-II-Ba $(\mathrm{OH})_{2}$

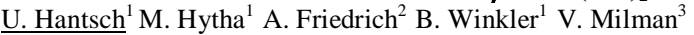

${ }^{1}$ CAU Kiel Institut Fuer Geowissenschaften / Kristallographie Olshausenstrasse 40 KIEL 24098 GERMANY ${ }^{2}$ Laboratorium f. Kristallographie, ETH Zuerich ${ }^{3}$ Accelrys Inc., Cambridge

The pressure dependence of the structural parameters and bonding characteristics of $\beta-\mathrm{Ba}(\mathrm{OH})_{2}$ and its high pressure modification $\beta$-II-Ba(OH $)_{2}$ have been investigated up to $20 \mathrm{GPa}$ by density functional theory (DFT) calculations using the generalized gradient approximation and a plane wave basis set in conjunction with ultrasoft pseudopotentials [1]. The agreement between the structural parameters obtained from theory $(a=9.459 \AA, b=7.939$ $\AA, c=6.811 \AA, \beta=95.6^{\circ}, S G=P 2_{1} / n$ and experiment [2] for the ground state structure is well within the usual limits of DFT-based calculations. Within the calculated pressure range no additional hydrogen bonding is induced whereas the coordination numbers of the atoms $\mathrm{Ba} 1$ and $\mathrm{Ba} 2$ change from 8 to 9 and 7 to 8 , respectively. For $\beta$-II- $\mathrm{Ba}(\mathrm{OH})_{2}$, the positions of the hydrogen atoms have been predicted. For $\beta-\mathrm{Ba}(\mathrm{OH})_{2}$, the elastic stiffness coefficients have been determined by finite strain calculations. From these data and from the calculated compression behaviour, the bulk modulus of $\beta-\mathrm{Ba}(\mathrm{OH})_{2}$ has been obtained. The finite strain calculation yields $\mathrm{B}=48.1(4) \mathrm{GPa}$, while the equation of state gives $\mathrm{B}=40.7(1.5) \mathrm{GPa}$ and a pressure derivative of $\mathrm{B}, \mathrm{B}=$ 4.9. The agreement with the experimental value $(B=39.5(1.3))$ [2] obtained by fixing $B$ to a value of 6 and fitting only data points below the expected phase transition is satisfactory.

We are grateful to the Deutsche Forschungsgemeinschaft for financial support in the framework of the 'Strukturgradienten program.

[1] Milman et al. (2000) Int. J. Quantum Chem. 77, 895-910 [2] Friedrich (2001) Acta Cryst. B 57, 747-758

Keywords: HIGH PRESSURE, AB INITIO CALCULATIONS, HYDRATES 